\title{
ATRASO E FORMAÇÃO DUAL NA PRODUÇÃO DO ESPAÇO TOCANTINENSE
}

\author{
DELAY AND TRAINING DUAL IN PRODUCTION OF TOCANTINS SPACE
}

\author{
RETARD ET FORMATION DUAL EN LA ZONE DE PRODUCTION \\ DE TOCANTINS
}

Eliseu Pereira de Brito - Universidade Federal do Tocantins - Araguaína - Tocantins - Brasil eliseubrito@uft.edu.br

\section{Resumo}

Este artigo trabalha com a formação socioespacial do Estado do Tocantins e tem como principal objetivo identificar a dualidade básica da economia tocantinense. A partir de uma leitura Rangel (2005), entendeu-se que há uma heterogeneidade na formação socioespacial brasileira que precisa ser melhor estudada e compreendida. Assim, utilizando-se de um estudo analítico da metodologia proposta por este autor sobre a dualidade da economia brasileira, tornou-se possível visualizar algumas questões pertinentes ao pacto de poder regional e do antigo Estado de Goiás estruturante da economia do Tocantins.

Palavras-chave: Dualidade da economia, formação socioespacial, criação do Tocantins.

\section{Abstract}

This article deals with the spatial and social formation of the Tocantins State and the main objective is to identify the Basic Economics Duality of Tocantins. And from a determined reading on Rangel (2005) we believe that there is a kind of heterogenity in the Brazilian spatial and social formation that needs to be better studied and understood. Thus, when using an analytical methodology proposed by this author, about the Economics Duality of the Brazilian people, it is possible to view some issues related to the agreement of regional resources and the former State of Goiás, being the economy structure of Tocantins.

Key words: Economics duality, social and spatial formation, Tocantins foundation.

\section{Résumè}

Cet article traite de la formation socio-spatiale de l'Etat de Tocantins et son objectif principal c'est d'identifier la dualité fondamentale de l'économie de Tocantins. À la lecture sur Rangel (2005) croit qu'il existe une hétérogénéité dans la formation socio brésilienne qui doit être mieux étudié et compris. Ainsi, en utilisant une méthodologie d'analyse proposée par cet auteur, sur la dualité de l'économie brésilienne, il est devenu possible de voir certaines questions relatives à l'accord de puissance régionale et l'ancien Etat de Goiás, un structurateur de l'économie de Tocantins.

Mots clés: La dualité de l'économie, formation socio-spatiale, création de Tocantins.

\section{Introdução}

O Estado do Tocantins, região anteriormente conhecida como norte goiano ou norte de Goiás, foi criado a partir da divisão do Estado de Goiás no ano de 1988. Toda esta distinção foi pela sua peculiaridade no que tange à formação espacial. O sul de Goiás era desenvolvido em comparação 
com o norte de Goiás, que era atrasado ou ainda estava em processo de desenvolvimento. A modernização agrícola de Goiás diferenciou a região sul da região norte e as assimetrias foram notórias, desencadeando vários movimentos separatistas, o que culminou em 1988 com a criação do Estado do Tocantins.

Entender o processo da formação espacial deste novo estado é o objetivo maior deste trabalho. Para tanto, partiu-se das orientações estabelecidas por Rangel $(1981,2005)$ sobre a formação espacial do Brasil como suporte para este estudo. As dualidades foram analisadas a partir de uma construção da história regional, sendo as obras de Parente (2007) e Valverde (1981) trabalhos norteadores do estudo histórico do estado. Para entender o contexto local, utilizou-se das pesquisas de Valverde e Dias (1967) e Furtado (2005).

Esse estudo buscou comparar os pactos da dualidade da economia nacional com os pactos da economia regional, descobrindo, recriando, absorvendo, a partir destas análises, uma identificação da dualidade básica da economia tocantinense. O presente artigo inicia com a descrição e a discussão acerca da importância da análise da dualidade da economia brasileira e, em seu desenvolvimento, analisa o papel do Estado de Goiás e a contribuição da dualidade regional para a construção e formação espacial do Estado do Tocantins.

\section{Uma leitura em Ignácio Rangel}

Rangel (1981 e 2005) entendeu o processo histórico da economia brasileira como constituído por fases sucessivas de dualidades. Cada uma dessas fases comportava formações econômicas dominantes, tendo uma situada no polo externo, e outra, no polo interno da economia. Estas duas formações básicas da economia, controlada por leis próprias, estabelecemse no território demonstrando um permanente conflito entre si, por serem dominantes em seus espaços.

Neste sentido, ela é dual e simétrica à economia mundial, porém, segundo Pereira (1993), a história do Brasil não refletiu fielmente a história europeia; tal fato se deu porque a evolução aqui não foi autônoma e nem formada exclusivamente pelas suas forças internas. Isso implica dizer que a coexistência dual de relações históricas no país é defasada em relação à existente na Europa. 
A organização do poder no Brasil abriu a possibilidade de escolher sobre quais alicerces apoiar a economia, tendo como base uma potência mundial. Observando tal desenvoltura da economia, a formação dual brasileira, ao confrontar-se com a expansão de suas forças produtivas, reagiu como as demais formações sociais, mudando o seu modo de produção para outro que apresentava estágio tecnologicamente mais avançado.

A formação dual da sociedade brasileira mostra que o poder político é exercido sempre por duas forças majoritárias. Enquanto uma força ocupa o poder, surge uma nova força para substituí-la no poder. São organizações de classes dirigentes, simultaneamente conflitantes e solidárias. Daí poder-se falar de pacto de poder.

O lado externo do polo situa-se fora do país, é o modo de produção ativo nos centros mundiais aos quais a economia está ligada. Dessa forma, sobram três lados que disputam as duas representações de classe dirigente no país.

A dualidade da economia é explicada pela existência de dois polos e é sobre esses que se definem os lados e, consequentemente, os sócios. No polo interno situam-se, internamente, as relações de produção dominantes, correspondentes à classe dominante, chamada de sócio maior. No polo externo, situam-se as relações de produção emergentes, chamadas de sócio menor. Vale ressaltar, contudo, que os sócios nem sempre estão em apenas um polo. Isso varia de acordo com a organização da economia.

Como forma de melhor explicitar esta formação na região faz-se necessário trabalhar em sua particularidade, relacionando a dualidade econômica brasileira à dualidade econômica regional.

\section{A organização econômica do norte goiano na primeira dualidade} da economia brasileira

Para Rangel (2005), a vinda da família real para o Brasil e a abertura dos portos às nações amigas, possibilitou o início da organização do polo externo brasileiro. Os representantes desse polo eram então os comerciantes, em sua maioria não brasileiros, com pouca expressão política, formando o sócio menor do poder. Para Pereira (1993), esta dualidade foi caracterizada pelo latifúndio feudal, que não é igual ao latifúndio medieval da Europa ou ao asiático, mas em sua essência lembra o sistema que se constituía pela presença do servo feudal. 
Neste ponto, para Valverde (1985, p. 33), todo o crescimento econômico das lavouras do café veio em decorrência do trabalho escravo: "o Brasil é o café; o café é o negro". A dimensão do tráfico de escravos na primeira metade do século XIX foi grande, e mesmo com a promulgação de uma lei em 7 de novembro de 1831 dando liberdade aos escravos que chegassem no país a partir daquela data, o tráfico continuou a existir tornando a lei sem efeito, pois as oligarquias que na época comandavam o país não acataram a decisão legal. "A escravatura estava fadada ao desaparecimento, mas os fazendeiros de café estavam, geralmente, por demais dependentes dela para que quisessem abrir mão do trabalho escravo" (Valverde, 1985, p. 35).

A expansão da economia açucareira impulsionou a necessidade de aumento da criação de gado. Com a escassez da lenha e com os danos provocados à lavoura, tornou-se necessário encontrar novas áreas para a criação do gado que não fossem litorâneas. A interiorização da criação de gado foi importante para a ocupação das terras das porções centrais do país. Mas essa era uma economia a princípio muito reduzida, pois não ultrapassava os 5\% do valor da exportação açucareira do Nordeste.

Segundo Furtado (2005), o litoral não possuía também boa qualidade de pastos para abrigar o gado, o que, no começo do século XVII, justificava ainda mais a rápida penetração pelo sertão, ultrapassando o rio São Francisco, alcançando o rio Tocantins e estendendo-se daí para o norte do Estado do Maranhão. Quanto mais os produtores se interiorizavam, mais oneroso ficava o transporte do gado até as regiões litorâneas. Com os lucros caindo, o interesse pela criação de animais também diminuía e, ao mesmo tempo, a relação de trabalho se diversificava entre os meeiros, os indígenas e escravos. Era uma atividade em grande parte de subsistência, uma vez que se aproveitava tudo o que o gado oferecia para garantir a sobrevivência no sertão. Este modelo econômico acabou transformando a economia nordestina produtora do açúcar em uma economia de subsistência, da pecuária extensiva. Para Valverde (1985, p. 163), "foi pelas fazendas de criação que se povoou todo o Piaú e o sul do Maranhão até as barrancas direitas do Tocantins".

Para Lira (2007), a plantação da cana no litoral foi uma das principais causas do avanço da pecuária pelo sertão. As frentes nordestinas da pecuária avançaram as barreiras do rio São Francisco e ocuparam o sul do Maranhão no século XVIII. Atravessaram o rio Tocantins no século XIX e ocuparam o norte de Goiás (Tocantins). Posteriormente, avançaram 
um pouco mais rumo à fronteira oeste, ultrapassando o rio Araguaia e ocupando o sudeste do Pará.

Esta organização possibilitou a formação do sócio menor, constituído por pequenos proprietários de rebanhos que viviam isolados especificamente na porção norte, uma vez que, em decorrência da economia açucareira, houve uma interiorização desta atividade no sul do Maranhão e no norte de Goiás (Tocantins). Era uma atividade de subsistência, mas que mantinha uma relação comercial do excedente da produção com os engenhos do Nordeste, caracterizando, por isso, um tipo de capitalismo mercantil.

Em se tratando da economia mineira, Furtado (2005) afirma que a base desta era o trabalho escravo, mas em moldes diferentes daqueles encontrados na economia açucareira. Nessa, a forma como se organizava o trabalho permitia que o escravo tivesse maior iniciativa; muitos deles chegaram mesmo a trabalhar por conta própria, comprometendo-se a pagar periodicamente uma quantia fixa ao seu dono, o que abria a possibilidade de comprar a própria liberdade.

Outra questão que merece destaque é que as relações que se estabeleciam com a terra na mineração eram diferentes da açucareira, pois havia uma instabilidade quanto ao lucro advindo da terra. O garimpo e o lucro eram incertos.

Observa-se nesse contexto regional em crise, que os antigos mineradores, agora pecuaristas, constituíam o sócio maior que mantinha suas áreas de influência de norte a sul da região, dominando, principalmente, as relações com a Bahia (Parente, 2007). Sua área de concentração maior ainda era o Polígono do Ouro (sul da região).

A organização econômica do norte goiano na segunda dualidade da economia brasileira

Se, na primeira dualidade, os senhores de escravo eram o sócio maior e os comerciantes, o sócio menor, na segunda dualidade, com a precarização do modo de produção escravista, o capitalismo mercantil passou a ser sócio maior, respaldado sobre o capitalismo industrial no lado externo do polo externo.

Na segunda dualidade brasileira, segundo Rangel (2005, p. 674), essa divisão apresentava a seguinte configuração: o "sócio maior: a burguesia comerciante, representativa do polo externo; o sócio menor: os 
fazendeiros, latifundiários feudais, por um lado, e comerciantes, por outro, representando o polo interno".

Na Amazônia, na porção leste da região também chamada de matas do Pará, os nordestinos que para lá se dirigiam, desde cedo faziam dívida nos acampamentos. Deviam o transporte até a floresta, a alimentação e utensílios de trabalho. Tal situação fez com que eles tivessem de complementar sua renda com a caça, pesca e coleta de frutos.

No sul da região norte goiana, a pecuária era extensiva e não se constituía na formação de riqueza no final do século XIX e início do século XX. Vale ressaltar que a pecuária nesta porção do território não surgiu pelo engenho; foi a mineração que introduziu a atividade. Com a sua crise, ela se tornou uma atividade de subsistência que, segundo Barbosa (1999), firmava-se no território e consolidava uma nova classe que surgia: a dos pecuaristas.

A porção norte da região (região do Bico do Papagaio) se integrava à economia maranhense abastecendo os mercados por meio do excedente da agricultura e pecuária. A porção sul ainda vivia sem criar novas alternativas comerciais com o mercado baiano, que se fortalecia com a produção do cacau. Para Andrade (1994, p. 127), a parte sul da região "foi ocupada por criadores de gado vindos do Vale do São Francisco, que visavam ao abastecimento dos mineradores, e por pequenos produtores agrícolas, que faziam uma agricultura de alimentos". Isto mostra que, com o declínio da mineração, houve também um declínio da atividade pecuária que se aprofundou ainda mais com as quedas das importações para a Bahia.

Ao norte, a pecuária tornou-se atividade principal e articulouse com a economia da borracha e da castanha que economicamente atingia seu auge. $\mathrm{O}$ abastecimento das áreas de exploração vegetal foi importante para o desenvolvimento da pecuária. Estruturada e articulada ao território, as oligarquias formadas pela pecuária e pela agricultura no sul do Maranhão e norte do Tocantins se consolidaram como sócio menor. Em contrapartida, o sul de Goiás mantinha relações importantes com a capital de Goiás e com a oligarquia latifundiária, que comandava o poder apoiada pelos cafeicultores de São Paulo. Esses, empobrecidos, não chegavam a constituir o sócio menor, uma vez que esse sócio se formou pelo capitalismo mercantil, estabelecido ao longo dos rios Tocantins e Araguaia sobre o comando de Dianópolis, Porto Nacional, Pedro Afonso, Carolina e Conceição do Araguaia. 
A organização econômica do norte goiano na terceira dualidade da economia brasileira

A terceira dualidade teve início após a Primeira Guerra Mundial. Neste período surgiu a necessidade de a classe comerciante internalizar o modo de produção dominante. Esta classe era a sócia maior da segunda dualidade e, portanto, estritamente ligada ao capitalismo industrial europeu, representando o lado interno do polo externo. Mas, com a queda do comércio exterior, seguida da subtração da capacidade de importar, pressionava por uma substituição de importações.

Para Campos (2004, p. 20), "a corrente migratória que demanda a Goiás dirige-se para o campo”. Como a pecuária enfrentava uma crise estrutural, houve uma canalização de recursos para a agricultura, "a pecuária deixa de ser a principal riqueza, e a agricultura, com a produção do arroz, assume o primeiro lugar em importância na renda do estado" (Campos, 2004, p. 23). Em se tratando do norte goiano, levou-se em consideração que a área ficou à mercê do investimento e teve na pecuária sua base econômica.

Lira (1995) trabalhou com duas forças que nasceram com o movimento de 1930: de um lado os pactos de poder estaduais, organizados pelo latifúndio que queria ter suas terras improdutivas sem preocupação com as políticas adversárias; de outro, o pacto federalista, formado pelos coronéis que buscavam uma organização mais ampla com base no coronelismo e no rompimento do poder dos latifundiários.

Havia dois desenvolvimentos em Goiás, um comandado pelo sul ligado à elite agrária conservadora, e outro isolado e localizado no norte, subdividido em dois blocos: o extremo norte e o centro-norte. Nesse último, o campo da disputa político-econômica foi fértil para o desenvolvimento do coronelismo, com hegemonia do poder local, mantendo suas extensões de poder desde Porto Nacional, Dianópolis e Tocantinópolis (Lira, 1995).

O norte e o sul de Goiás historicamente tiveram conflitos. Mas vale frisar que, dentro da história política de Goiás, o latifúndio sofreu derrota no pacto de poder na terceira dualidade. Esse era apoiado pelas oligarquias paulistas do café, comandado principalmente pelos Caiado, que dominavam o cenário político-econômico goiano. A ampliação do território de suas influências à coluna mineira deu condições para a instalação da burguesia industrial no poder, comandada por Pedro Ludovico Teixeira. 
O investimento no setor agrícola foi prioridade dos governos de Goiás neste período. A expansão da fronteira agrícola pela Amazônia conduziu à política de infraestrutura, que teve na rodovia Belém-Brasília seu marco principal, pois trouxe para o Tocantins uma nova organização do território, possibilitando uma expansão da agricultura mecanizada pelas áreas a oeste do rio Tocantins. Os corredores das margens dos rios Araguaia e Tocantins não acompanharam a proporção do desenvolvimento que esta rodovia trouxe à pecuária do norte do Tocantins.

A quarta dualidade básica da economia brasileira e a conservação/substituição das estruturas dos pactos do poder no Tocantins

Com o advento da quarta dualidade básica da economia brasileira na década de 1980, algumas alterações foram desencadeadas na região. A consolidação das cidades de Araguaína ao norte e Gurupi e Palmas ao sul firmaram os pactos de poder que, a partir das alianças regionais, se sobressaíram. Alguns cuidados têm que ser tomados para a análise da região, uma vez que haverá uma tendência de continuação das oligarquias no poder, porém, com um processo de substituição.

A quarta dualidade brasileira teve início provavelmente com a queda da Ditadura Militar na década de 1980. Na década anterior, o Brasil experimentou um plano de crescimento denominado "Milagre Econômico" que norteou seus investimentos por meio do II PND 1975/1979. O investimento na produção de bens de capital e na tecnicização da agricultura no cerrado foram medidas impactantes para a área central do país.

No Tocantins, a formação espacial vai se distanciar dos estágios da formação econômica brasileira. Os parques industriais tiveram uma organização muito tenra, ou inexistente em algumas áreas. Por este motivo, não dá para analisar a região como homogênea no quesito economia, que é muito diversificada nesta porção do território brasileiro.

Até a década de 1990, não se identifica uma sobreposição de sócios no pacto de poder, havendo uma perpetuação dos poderes oligárquicos agrícolas. Acredita-se que o sócio maior era constituído pela burguesia rural que tinha na pecuária sua base estruturada e já madura da economia regional. O sócio menor era formado pela agricultura dos anos de 1970, que se consolidou com grandes projetos agrícolas na década seguinte. 
A configuração das oligarquias em Goiás foi decisiva para delinear as políticas e a organização territorial tocantinense. De tradição agrícola, esta organização só foi modificada nos anos de 1930 com a construção de Goiânia: "a letargia que dominava na economia goiana só seria quebrada a partir da Revolução de 1930, quando a oligarquia dos Caiado foi apeada do poder e um novo líder, Pedro Ludovico, construiu a cidade de Goiânia para ser a nova capital do estado" (Andrade, 1994, p. 128). Mas a burguesia industrial que nascia em Goiás (Goiânia, Anápolis e no entorno de Brasília) fez um pacto com a oligarquia agrária. O PSD se uniu à UDN e as duas forças políticas formaram a ARENA que seria a principal sigla partidária da época. Até 1969, não havia representante no executivo e no legislativo em Goiânia, quando foi alçado ao poder Leonino Caiado (ARENA), prefeito da capital, representando a velha guarda da UDN.

O MDB ficou articulado entre a burguesia industrial e a burguesia do agronegócio, tendo como seu núcleo de apoio as grandes cidades goianas e a cidade de Porto Nacional, principal foco do MDB no norte goiano. As áreas do extremo norte (Bico do Papagaio e de Araguaína) eram núcleos de apoio à oligarquia conservadora ligada aos Caiado e à ARENA. Tratando sobre esta questão, Borges (2004, p. 140) diz que o "MDB aumenta sua bancada através da eleição de políticos com votação principal nas cidades maiores, como Goiânia e Anápolis". Mas, o “norte mantém presença na Assembleia Legislativa por meio da eleição de deputados locais na sigla situacionista”, o que quer dizer, na ARENA.

Com o desgaste da Ditadura Militar, o MDB ganhou forças e conseguiu votação expressiva no Estado. O foco oposicionista da capital e da burguesia industrial e urbana tornou-se marca da política em Goiás. Os votos do norte já não se mostravam situacionistas e houve um ligeiro crescimento dos votos oposicionistas, sustentados pelos eleitores da cidade do Porto Nacional. Conforme declara Borges (2004),

o PDS mantém a maior parte de seu domínio nas regiões ao norte. Apenas no Bico do Papagaio e no nordeste meridional, o partido governista faz maior número de prefeitos que o PMDB. O extremo oposto se verifica nos municípios da Serra Dourada, Pirineus, Goiânia e Porto Nacional, onde a oposição ganha todos os executivos locais. (Borges, 2004, p. 171)

Os ruralistas liderados pelos Caiado e seus aliados invadiram os cargos do legislativo de Goiás e passaram a defender a criação do Estado 
do Tocantins como uma necessidade de manutenção do poder, uma vez que aumentaria a bancada ruralista na Câmara e no Senado Federal, já que se criava um estado totalmente dominado pela UDR.

Desta forma, no ano de 1988 o cenário político-econômico na região é constituído pelo sócio maior, comandado pela cidade de Araguaína que articulava o poder sobre o norte da região na hegemonia da produção pecuarista. Há uma gestão do território na prestação de serviços ligados à pecuária na cidade de Araguaína e a criação de gado, tanto no município como na região norte do Tocantins, em detrimento do sul. Com mais de 90\% de toda arrecadação (pecuária) do estado em 1989, e tendo uma base consolidada que já vinha desde a construção da rodovia Belém-Brasília, esta é a região com maior poder econômico e político do Estado do Tocantins.

A elite agrícola, que inicialmente parecia uma organização social, não passava de um empresariado agrícola nascente. Para Barbosa (1996, p. 114) "tendo em vista a formação de cooperativas, no Projeto Rio Formoso estas se assemelhavam mais a empresas capitalistas ou sociedades anônimas que de fato cooperativas”. A forma de implantação proporcionou o enriquecimento e formação de pessoas abastadas e com influência política.

A concentração da produção de grãos no Tocantins deu-se na região de Gurupi. Com mais de $73 \%$ de toda a arrecadação estadual no setor, consolidou-se como o principal centro econômico da agricultura no estado, disputando força hegemônica com a cidade de Araguaína, ao norte.

\section{Conclusão}

A leitura da dualidade básica da economia brasileira nos permite afirmar que os espaços são diferenciados em sua formação no Brasil. Essa diferenciação se verifica a partir do momento em que comparamos o processo e a estrutura de uma região com outra dentro do país. No que tange à relação proposta neste trabalho sobre os pactos de poder e a dualidade da economia brasileira, a pesquisa possibilitou entender minuciosamente os entremeios de uma formação regional.

Para Ignácio Rangel, há uma heterogeneidade na formação socioespacial brasileira que precisa ser melhor compreendida. Assim, utilizando 
um estudo analítico da metodologia proposta por ele, analisamos algumas questões pertinentes ao pacto de poder regional e do antigo Estado de Goiás, estruturante da economia do Tocantins.

A dualidade da economia no norte goiano, hoje Tocantins, aconteceu diferentemente do ocorrido no Sudeste do Brasil, e até mesmo, do sul de Goiás. Enquanto no Sudeste, na primeira dualidade, a produção baseava-se no escravismo nas lavouras, naquela região, o escravismo dos garimpos foi substituído pelo latifúndio, que se tornaria dominante no Brasil na segunda dualidade. Na terceira dualidade, o Brasil passou a ser industrial, porém, no Tocantins, não houve substituição dos pactos de poder. As oligarquias apenas mudavam de local ou diversificavam a produção agrícola. Com esta análise, podemos concluir que embora haja sempre um grupo que comanda os centros de decisão do país, este mesmo país é heterogêneo, mutante nas suas várias localidades.

\section{Referências}

ANDRADE, Manoel C. de. Nordeste, espaço e tempo. Petrópolis (RJ): Vozes, 1970. (Coleção Caminhos Brasileiros, 5)

ANDRADE, Manoel C. de. Modernização e pobreza: a expansão da agroindústria canavieira e seu impacto ecológico e social. São Paulo: EUEP, 1994.

BARBOSA, Ycarim Melgaço. As políticas territoriais e a criação do estado do Tocantins. Tese (Doutorado) - FFLCH, Universidade de São Paulo, São Paulo, 1999.

BORGES, Pedro Célio Alves (A). O Bipartidarismo autoritário em Goiás. In: SOUZA, Dalva B. (Org.). Goiás: sociedade e estado. Goiânia: Cânone Editorial, 2004.

BORGES, Pedro Célio Alves (B). Formação e representações do estado de Goiás. In: SOUZA, Dalva B. (Org.) Goiás: sociedade e estado. Goiânia: Cânone Editorial, 2004.

BRITO, Eliseu Pereira de. Uma decisão, um projeto, um sonho e discursos na criação e consolidação de Palmas. In: XV Encontro nacional de geógrafos. São Paulo, 2008.

BRITO, Eliseu Pereira de. O papel de Palmas na rede de integração regional. Dissertação (Mestrado) - Universidade Federal da Grande Dourados, Dourados (MS), 2009.

CAMPOS, F. Itami. A política tradicional em Goiás: 1930 a 1960. In: SOUZA, B. Dalva (Org.). Goiás: sociedade e estado. Goiânia: Cânone Editorial, 2004.

CARVALHO, Francisquinha Laranjeira. Fronteira e conquistas pelo Araguaia século XIX. Goiânia: Kelps, 2006. 
FURTADO, Celso. Formação econômica do Brasil. 32. ed. São Paulo: Companhia Editora Nacional, 2005.

GOMES, Horieste; TEIXEIRA NETO, Antônio; BARBOSA, A. Sales. Geografia: Goiás/Tocantins. 2. ed. revista e ampliada. Goiânia: Ed. UFG, 2005.

LIRA, Elizeu Ribeiro. A frente pastoril e a (des)organização dos territórios indígenas no sul do Maranhão e no antigo norte de Goiás. Revista plurais. Anápolis: Revista eletrônica, v. 1, n. 4, 2006. Disponível em: http://www.nee.ueg. br. Acesso em: 24/11/2008.

LIRA, Elizeu Ribeiro. A gênese de Palmas (TO). Dissertação (Mestrado) - Unesp, Presidente Prudente, 1995.

LOUREIRO, Violeta R. A história social e econômica da Amazônia. Pará, Secretaria de Estado de Educação. Estudos e problemas amazônicos: história social e econômica e temas especiais. 2. ed. Belém: CEJUP, 1992.

PARENTE, Temis G. O ouro como fonte de atraso. In: Odair Giraldin (Org.). A (trans)formação histórica do Tocantins. 2. ed. Goiânia: Ed. UFG, 2002. p. 171-182.

PARENTE, Temis G. Fundamentos históricos do Estado do Tocantins. 3. ed. Goiânia: Ed. UFG, 2007.

PEREIRA, Luiz Carlos Bresser; REGO, José Marcio. Um mestre da economia brasileira: Ignácio Rangel. Revista de economia política, São Paulo, v. 13, n. 2, abr./jun. 1993.

RANGEL, Ignácio. História da dualidade brasileira. Revista de economia política. São Paulo, out./dez 1981.

RANGEL, Ignácio.Economia: milagre e antimilagre. Rio de Janeiro: Jorge Zahar, 1986.

RANGEL, Ignácio. Obras reunidas. Rio de Janeiro: Contraponto, v. 1 e 2, 2005.

RIBEIRO, Miguel A. Campos. A complexidade da rede urbana amazônica: três dimensões de análise. Tese (Doutorado) - Universidade Federal do Rio de Janeiro, 1998.

ROCHERFORT, Michel. Redes e sistemas. Ensinando sobre o urbano e a região. Tradução de Antônio de Pádua Danesi. São Paulo: Hucitec, 1998.

SANTOS, Milton. A natureza do espaço: técnica e tempo/razão e emoção. São Paulo: Hucitec, 1996.

SANTOS, Milton. Da totalidade ao lugar. São Paulo: Edusp, 2005. (Coleção Milton Santos).

VALVERDE, Orlando. Estudos de geografia agrária brasileira. Petrópolis (RJ): Vozes, 1985.

VALVERDE, Orlando; DIAS, Catarina Vergolino. A rodovia Belém-Brasília: estudo de geografia regional. Rio de Janeiro: Fundação Instituto Brasileiro de Geografia, 1967.

VALVERDE, Orlando. Estudos de geografia agrária brasileira. Petrópolis: Vozes, 1985. 
VICENTINI, Yara. Cidade e história na Amazônia. Curitiba: Ed. UFPR, 2004.

Eliseu Pereira de Brito - Mestre em Geografia pela Universidade Federal da Grande Dourados. Professor Assistente do Curso de Geografia da Universidade Federal do Tocantins.

Recebido para publicação em janeiro de 2011 Aceito para publicação em maio de 2011 